\title{
Qualidade microbiológica do leite determinada por características de produção
}

\author{
Microbiological quality of milk determined by production characteristics
}

\author{
Luís Augusto NERO ${ }^{1 \star}$, Gabriela Nogueira VIÇOSA ${ }^{1}$, Flávio Evans Vilela PEREIRA ${ }^{1}$
}

\begin{abstract}
Resumo
A atividade leiteira vem se tornando cada vez mais importante para a economia brasileira, apesar de ainda ser caracterizada como típica de pequenos produtores com baixa produtividade. Devido a esse perfil ocorre pouco investimento na atividade resultando em uma produção leiteira com baixa qualidade, identificada por altas contagens microbianas. O objetivo deste trabalho foi estabelecer uma relação entre práticas higiênicas de ordenha e a qualidade microbiológica do leite. Assim, um questionário sobre características de produção, ordenha e cuidados sanitários foi aplicado em 60 propriedades leiteiras localizadas na região de Viçosa, MG - Brasil, das quais foram coletadas amostras de leite para enumeração de aeróbios mesófilos (AM) e psicrotróficos (PSI). A maioria das propriedades foi caracterizada como pequena, com menos que 15 animais em lactação e produção diária menor que $50 \mathrm{~L}$. De forma geral, verificou-se que os produtores adotam várias práticas higiênicas, mais frequentes em propriedades com produção diária superior a $100 \mathrm{~L}$ de leite (significativa em relação a pré e pós-dipping e uso do CMT). O reflexo dessas práticas foram as baixas contagens de AM e PSI nas amostras analisadas, com médias menores de forma significativa em propriedades que refrigeram a produção (Tukey, $\mathrm{p}<0,05$ ).
\end{abstract}

Palavras-chave: características de produção; práticas de ordenha; aeróbios mesófilos; psicrotróficos; refrigeração.

\begin{abstract}
Milk production has been considered increasingly important in the Brazilian economy despite being characterized as typical practice of small producers with low productivity. Nevertheless, little financial investment has been made resulting in low quality milk production with high microbiological counts. The objective of this work was to establish a relation between hygienic practices of milking and production and the microbiological quality of milk. A questionnaire focusing on the characteristics of production, milking, and sanitary conditions was administered in 60 milk farms in the city of Viçosa, $M G$ - Brazil, from which milk samples were collected for determining the counts of mesophilic aerobes (MA) and psychrotrophics (PSI). The majority of the producers was characterized as small with less than 15 animals in lactation and daily average production less than $50 \mathrm{~L}$. Hygienic practices were adopted by the majority of producers, mainly by those with average daily production higher than $100 \mathrm{~L}$ (significant considering pre and post-dipping, and CMT). The result of the application of these practices was the low counts of MA and PSI with lower averages in milk farms that use refrigeration after milking (Tukey, p $<0.05$ ).

Keywords: production characteristics; milking practices; mesophilic aerobes; psychrotrophics; refrigeration.
\end{abstract}

\section{Introdução}

Em 2005 o Brasil produziu 23.320 .000 toneladas de leite, o que posicionou o país como sétimo maior produtor mundial e gerou um lucro de 12.572 milhões de reais (EMBRAPA GADO DE LEITE, 2007). Esses valores expressivos mostram a relevância da atividade leiteira para a economia brasileira, tanto no cenário interno como no externo. Como consequência, a produção leiteira no Brasil vem crescendo nos últimos anos em conjunto com a exportação, revelando seu grande potencial de desenvolvimento e consolidação como produto de importância na economia nacional (EMBRAPA GADO DE LEITE, 2007).

As características da produção leiteira no Brasil são os principais fatores que impedem um desenvolvimento mais acelerado dessa atividade. De forma geral, a maior parte dos produtores pode ser classificada como pequenos ou médios, com produção diária de 50 a 100 L e de caráter familiar (EMBRAPA GADO DE LEITE, 2007; BRITO et al., 2004). Como consequência ocorre pouco investimento na atividade, resultando em problemas em toda a cadeia produtiva, como baixa tecnificação, falta de controle sanitário dos animais e condições higiênicas inadequadas durante a ordenha, conservação e transporte (SANTOS; FONSECA, 2007; VALEEVA et al., 2005). Os reflexos dessas deficiências da produção leiteira são observados na baixa produtividade do rebanho nacional (apenas $1.219 \mathrm{~L} / \mathrm{vaca} /$ ano em 2005, EMBRAPA GADO DE LEITE, 2007) e na baixa qualidade do leite produzido.

A baixa qualidade do leite cru é notoriamente conhecida em todo o território nacional, e como consequência resulta em produtos beneficiados de qualidade insatisfatória (ARCURI et al., 2006; ROCHA et al., 2006; NERO et al., 2005; NERO et al., 2004; GUIMARÃES, 2002; SILVA et al., 2001; BELOTI et al., 1999; SILVEIRA et al., 1989). O principal parâmetro utilizado para se verificar a qualidade desse produto é o seu perfil microbiológico, determinado principalmente pela forma de obtenção, armazenamento e transporte. Grupos específicos de microrganismos são pesquisados para esse fim, como os aeróbios mesófilos, coliformes e psicrotróficos (CHAMBERS, 2002; GUIMARÃES, 2002). A presença de altos níveis de contaminação microbiana em leite e em seus derivados compromete a durabilidade desses produtos, já que

${ }^{1}$ Departamento de Veterinária, Universidade Federal de Viçosa - UFV, Av. PH Rolfs, s/n, Centro, CEP 36570 000, Viçosa, MG, Brasil, E-mail: nero@ufv.br

${ }^{*}$ A quem a correspondência deve ser enviada 
promovem a deterioração de seus componentes, como proteínas, gordura e açúcares (CHAMBERS, 2002; GRUETZMACHER; BRADLEY Jr., 1999).

Considerando os problemas inerentes da produção leiteira brasileira, o Ministério da Agricultura, Pecuária e Abastecimento (MAPA) iniciou na década de 1990 uma séria e extensa discussão nacional em busca de soluções e alternativas para melhorar a qualidade do leite e de seus derivados. O resultado desse esforço foi a publicação em 2002 da Instrução Normativa 51 (IN51) (BRASIL, 2002), que reúne novas normas de produção, identidade e qualidade de leites tipos A, B, C, pasteurizado e cru refrigerado, além de regulamentar a coleta de leite cru refrigerado e seu transporte a granel. Algumas modificações em relação aos parâmetros de qualidade do leite cru refrigerado ainda estão em andamento, devido a diferenças entre as características de produção nas diversas regiões do país. Porém, em todo o país já é exigida a conservação do leite cru sob refrigeração e o transporte granelizado às indústrias de beneficiamento (BRASIL, 2002).

Considerando as diferentes características de produção leiteira observadas no Brasil, esse estudo teve como objetivo verificar a interferência de diferentes práticas dessa atividade na qualidade microbiológica do leite cru.

\section{Material e métodos}

Considerando diferentes perfis de produção leiteira, 60 propriedades rurais da região de Viçosa, MG, foram selecionadas aleatoriamente para coleta de dados. Essa seleção teve como objetivo amostrar propriedades rurais que correspondessem às características gerais de produção leiteira da região. Em cada propriedade selecionada um questionário foi aplicado aos produtores rurais, abrangendo questões sobre características do rebanho e produção, procedimentos higiênicos durante a ordenha e com os animais (vacinação e controle de enfermidades) (Tabela 1).

Tabela 1. Características de produção leiteira avaliadas pelo questionário aplicado a produtores.
1. Produção leiteira
1.1. Quantidade de animais em lactação
1.2. Média de produção diária
2. Manejo de ordenha
2.1. Tipo de ordenha
2.2. Número de ordenhas diárias
2.3. Higienização dos utensílios (antes e após)
2.4. Higienização do ordenhador
2.5. Higienização dos animais
2.6. Descarte dos primeiros jatos
2.7. Pré-dipping
2.8. Pós-dipping
2.9. Refrigeração do leite após ordenha
3. Cuidados sanitários dos animais
3.1. Controle de mastites (realização de California Mastitis Test)
3.2. Tratamento de mastites
3.3. Vacinações
3.4. Controle de parasitas

Em paralelo à coleta de informações de produção, amostras de leite cru de cada propriedade foram coletadas em frascos estéreis e mantidas sob refrigeração durante o transporte até o processamento em laboratório. Todas as amostras foram diluídas em $\mathrm{NaCl}$ 0,85\% em escala seriada decimal até 1:1.000.000 para realização de análises microbiológicas. Considerando os níveis de contaminação esperados, 3 diluições de cada amostra foram selecionadas para enumeração de microrganismos aeróbios mesófilos (AM) e psicrotróficos (PSI). Todas as amostras coletadas foram submetidas à enumeração de AM de acordo com a metodologia descrita por Wher, Frank (2004), utilizando ágar padrão de contagem (PCA) com semeadura por profundidade e em duplicata, com incubação a $30^{\circ} \mathrm{C}$ por 72 horas. Para enumeração de PSI, amostras de 41 produtores foram semeadas de acordo com a metodologia descrita por Wher,Frank (2004), utilizando PCA com semeadura por superfície e em duplicata, com incubação a $7{ }^{\circ} \mathrm{C}$ por 10 dias. Os resultados finais obtidos para AM e PSI foram expressos em Unidades Formadoras de Colônias por $\mathrm{mL}$ (UFC. $\left.\mathrm{mL}^{-1}\right)$.

A caracterização da produção leiteira foi realizada calculando as frequências das diferentes respostas obtidas pelo questionário aplicado aos produtores e diferenças significativas foram calculadas pelo teste de $\chi^{2}(\mathrm{p}<0,05)$. Os resultados obtidos de contagens de AM e PSI foram inicialmente comparados com parâmetros de qualidade nacionais (BRASIL, 2002) e internacionais (CHAMBERS, 2002; SØRHAUG; STEPANIAK, 1997), e ainda convertidos em $\log _{10}$ para cálculo de médias e comparação por análise de variância (Tukey, $\mathrm{p}<0,05$ ) considerando diferentes características de produção. Todas as análises realizadas foram feitas utilizando o programa Statistica 6.0 (StatSoft Inc., Tulsa, O.K., E.U.A.).

\section{Resultados e discussão}

O questionário aplicado aos produtores de leite da região revelou um quadro bastante similar ao que é observado em outras regiões do Brasil (EMBRAPA, 2007; ARCURI et al., 2006; NERO et al., 2005; NERO et al., 2004). A maior parte dos produtores pode ser caracterizada como de baixa produção, já que $39(65,0 \%)$ relataram que possuem uma produção média diária de até $50 \mathrm{~L}$ de leite. Ainda quanto a essa característica, $11(18,7 \%)$ relataram uma produção entre 50 e 100 L diários e apenas 10 (16,7\%), com produção acima de $100 \mathrm{~L}$ diários. O perfil de pequena produção é confirmado pela pequena quantidade de animais em lactação. Em 51 propriedades $(85,0 \%)$ foram observados menos que 15 animais em lactação, 8 (13,3\%) apresentaram de 16 a 30 e em apenas $1(1,7 \%)$ foi verificado mais que 30 animais em lactação. A baixa produtividade da maioria dos produtores pode ser observada pelos dados apresentados na Tabela 2, que mostra a associação desses dois parâmetros e o predomínio de propriedades com baixa produção diária e pequena quantidade de animais em lactação.

Em relação ao manejo de ordenha, a maioria das propriedades rurais adotam o sistema de ordenha manual (57 propriedades, $95,0 \%)$, e apenas $3(5,0 \%)$ com ordenha mecânica em sistema semifechado (balde ao pé). Em nenhuma propriedade foi identificada a adoção de ordenha mecânica em sistema fechado. Apesar de representar um importante aspecto na tecnificação, a 
adoção de ordenha mecânica não indica necessariamente uma melhoria na qualidade do leite produzido, já que suas tubulações podem representar adicionais fontes de contaminação caso não ocorra uma higienização adequada (SANTOS; FONSECA, 2007; KLUNGEL et al., 2000). Outro indicativo da baixa produtividade é que a maioria dos produtores realiza ordenha apenas uma vez ao dia (37-61,7\%).

De forma geral é comum observar em pequenas propriedades leiteiras maior frequência de deficiências na produção (VALEEVA et al., 2005). Na Tabela 3 pode-se verificar as frequências de aplicação de importantes práticas na obtenção de leite em propriedades com diferentes níveis de produção diária. Podem ser observadas maiores frequências dessas práticas em propriedades leiteiras com média de produção diária superior a $100 \mathrm{~L}$, porém apenas em relação ao emprego do pré-dipping $\left(\chi^{2}=24,3 ; \mathrm{gl}=2 ; \mathrm{p}<0,01\right)$ e pós-dipping $\left(\chi^{2}=20,7 ; \mathrm{gl}=2\right.$; $p<0,01)$ essa frequência foi superior de forma significativa (Tabela 3).

O California Mastitis Test (CMT) ainda hoje é considerado como uma das principais ferramentas para se avaliar a ocorrência de mastites subclínica em rebanhos leiteiros (LEBLANC et al., 2006; RODRIGUES; RUEGG, 2005). A maioria dos produtores (41-68,3\%) não realiza o CMT como teste de triagem, verificando a presença de mastites apenas pelo descarte dos primeiros jatos em caneca de fundo escuro ( $43,2 \%$ dos que descartam) ou no chão $(9,1 \%$ dos que descartam). O emprego dessa prática foi detectado como sendo mais frequente de forma significativa $\left(\chi^{2}=27,5\right.$; $\mathrm{gl}=2 ; \mathrm{p}<0,01)$ em propriedades com produção diária maior

Tabela 2. Frequências de propriedades leiteiras agrupadas de acordo com a quantidade de animais em lactação e a produção média diária de leite.

\begin{tabular}{ccccc}
\hline \multirow{2}{*}{$\begin{array}{c}\text { Animais em } \\
\text { lactação (n) }\end{array}$} & \multicolumn{3}{c}{ Produção diária média (L) } & Total \\
\cline { 2 - 4 } & $<50$ & $50-100$ & $>100$ & \\
\hline$<15$ & $39(65,0 \%)$ & $9(15,0 \%)$ & $3(5,0 \%)$ & $51(85,0 \%)$ \\
$15-30$ & $0(0,0 \%)$ & $2(3,3 \%)$ & $6(10,0 \%)$ & $8(13,3 \%)$ \\
$>30$ & $0(0,0 \%)$ & $0(0,0 \%)$ & $1(1,7 \%)$ & $1(1,7 \%)$ \\
Total & $39(65,0 \%)$ & $11(18,3 \%)$ & $10(16,7 \%)$ & $60(100,0 \%)$ \\
\hline
\end{tabular}

que $100 \mathrm{~L}$ (Tabela 3). Apenas 14 (23,3\%) produtores relataram realizar tratamento de mastites quando identificadas, sendo a combinação cefoperazone sódio e acetato de dexametasona a mais utilizada $(35,7 \%)$. Todos os produtores relataram realizar o controle de parasitoses dos animas regularmente, sendo a ivermectina $(36,7 \%)$ o princípio ativo mais utilizado.

Considerando o controle de enfermidades infecto-contagiosas nos animais, todos os produtores relataram realizar vacinação contra febre aftosa, enquanto $19(31,7 \%)$ relataram vacinar contra carbúnculo e apenas $7(11,7 \%)$ contra raiva. Considerando a necessidade de vacinação de todos os animais contra brucelose, segundo recomendações do MAPA (Brasil, 2004), apenas $2(3,3 \%)$ produtores relataram não realizar vacinação, ambos com produção média de menos que $50 \mathrm{~L}$ por dia.

Grande parte dos produtores de leite apresentou produção leiteira com contagens de AM abaixo de parâmetros nacionais e internacionais (Brasil 2002; Chambers, 2002). De acordo com a IN51, o padrão de qualidade microbiológica adotado para o leite cru refrigerado atualmente na região Sudeste (onde se localiza a área de estudo) é uma contagem de AM máxima de $10^{6} \mathrm{UFC} \cdot \mathrm{mL}^{-1}$, e $47(78,3 \%)$ das amostras coletadas apresentaram contagens abaixo desse valor (Tabela 4). Entretanto, contagens de AM acima de $10^{5}$ UFC. $\mathrm{mL}^{-1}$ já são indicativas de sérios problemas higiênicos na obtenção, conservação e transporte do leite cru (CHAMBERS, 2002). Por essas razões, esse valor é a meta final de qualidade microbiológica que a IN51 pretende atingir a partir de 2011 para o leite cru refrigerado (BRASIL, 2002). Considerando essa meta, apenas $24(40,0 \%)$ produtores estariam com a produção dentro do parâmetro considerado adequado.

Os PSI são importantes na indústria láctea por serem deteriorantes e produzirem enzimas (proteases e lipases) termoestáveis, que podem permanecer viáveis mesmo após o processamento térmico (MARTINS et al., 2006; PINTO et al., 2006; MUNSH-ALATOSSAVA, ALATOSSAVA, 2006; SØRHAUG,STEPANIAK, 1997; GUINOT-THOMAS et al., 1995; KOHLMANN et al., 1991). O desenvolvimento desse grupo ocorre principalmente em condições inadequadas de refrigeração, com temperaturas variando entre 7 e $10^{\circ} \mathrm{C}$ (CHAMBERS, 2002; SØRHAUG, STEPANIAK, 1997). Apesar da importância desse

Tabela 3. Práticas higiênicas adotadas em propriedades leiteiras e médias de contagens de microrganismos aeróbios mesófilos (AM) e psicrotróficos (PSI) considerando diferentes volumes de produção média diária de leite.

\begin{tabular}{|c|c|c|c|c|}
\hline \multirow[t]{2}{*}{ Práticas higiênicas } & \multicolumn{3}{|c|}{ Propriedades leiteiras (produção média diária, L) } & \multirow[t]{2}{*}{ Teste } \\
\hline & $<50$ & $50-100$ & $>100$ & \\
\hline Higienização de utensílios (n;\%) & $39 ; 100,0$ & $11 ; 100,0$ & $10 ; 100,0$ & $\chi^{2}=0,0 ; \mathrm{gl}=2 ; \mathrm{p}=1,0^{\mathrm{ns}}$ \\
\hline Higienização do ordenhador (n;\%) & $32 ; 82,1$ & $11 ; 100,0$ & $9 ; 90,0$ & $\chi^{2}=1,8 ; \mathrm{gl}=2 ; \mathrm{p}=0,4^{\mathrm{ns}}$ \\
\hline Higienização dos animais (n;\%) & $32 ; 82,1$ & $10 ; 90,9$ & $10 ; 100,0$ & $\chi^{2}=1,8 ; \mathrm{gl}=2 ; \mathrm{p}=0,4^{\mathrm{ns}}$ \\
\hline Descarte dos primeiros jatos $(\mathrm{n} ; \%)$ & $26 ; 66,1$ & $9 ; 81,8$ & $9 ; 90,0$ & $\chi^{2}=3,7 ; \mathrm{gl}=2 ; \mathrm{p}=0,2^{\mathrm{ns}}$ \\
\hline Pré-dipping (n;\%) & $2 ; 5,1$ & $1 ; 9,1$ & $3 ; 30,0$ & $\chi^{2}=24,3 ; \mathrm{gl}=2 ; \mathrm{p}<0,01^{* *}$ \\
\hline Pós-dipping (n;\%) & $4 ; 10,3$ & $2 ; 18,2$ & $4 ; 40,0$ & $\chi^{2}=20,7 ; \mathrm{gl}=2 ; \mathrm{p}<0,01^{\star *}$ \\
\hline California Mastitis Test (n;\%) & $13 ; 33,3$ & $1 ; 11,0 \%$ & $5 ; 50,0$ & $\chi^{2}=27,5 ; \mathrm{gl}=2 ; \mathrm{p}<0,01^{\star *}$ \\
\hline Refrigeração após ordenha (n;\%) & $37 ; 94,9$ & $10 ; 90,9$ & $9 ; 90,0$ & $\chi^{2}=0,2 ; g l=2 ; p=0,9^{\text {ns }}$ \\
\hline AM (log UFC.mL $L^{-1}-$ média \pm desvio padrão) & $5,1 \pm 0,8^{\mathrm{b}}$ & $5,8 \pm 1,2^{\mathrm{a}, \mathrm{b}}$ & $6,2 \pm 1,2^{\mathrm{a}}$ & Tukey, $\mathrm{p}<0,05^{\star}$ \\
\hline PSI (log UFC.mL $L^{-1}-$ média \pm desvio padrão $)$ & $3,7 \pm 1,0^{\mathrm{a}}$ & $4,1 \pm 1,3^{\mathrm{a}}$ & $4,0 \pm 1,4^{\mathrm{a}}$ & Tukey, $\mathrm{p}<0,05^{\star}$ \\
\hline Total & $39 ; 100,0$ & $11 ; 100,0$ & $10 ; 100,0$ & \\
\hline
\end{tabular}

${ }^{\mathrm{n} s}$ sem diferença significativa; ${ }^{\star}$ médias com letras diferentes na mesma linha indicam diferença significativa (Tukey, $\left.\mathrm{p}<0,05\right)$; ${ }^{* *}$ diferença significativa $(\mathrm{p}<0,01)$. 


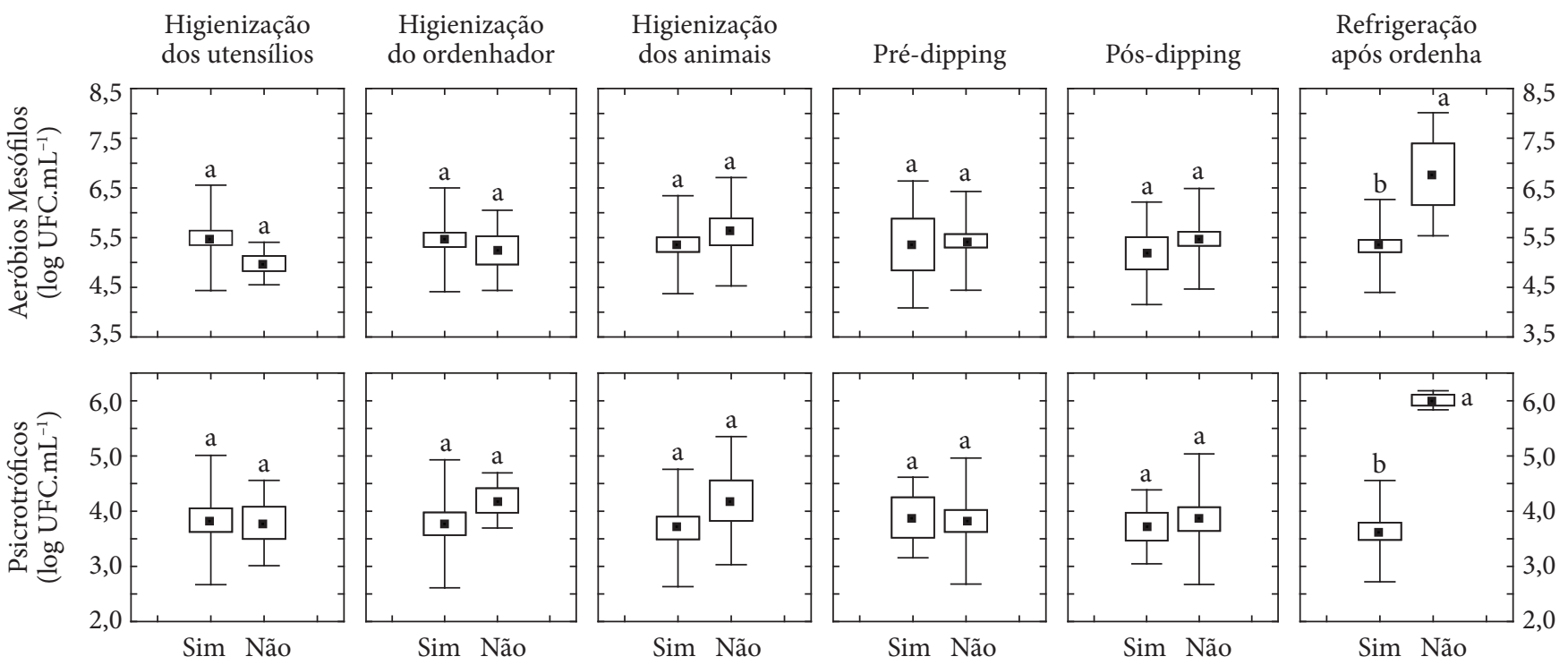

Figura 1. Médias de contagens de microrganismos aeróbios mesófilos e psicrotróficos em leite cru considerando diferentes práticas higiênicas adotadas durante a ordenha e conservação. Em cada gráfico, valores médios com letras diferentes indicam diferenças significativas (Tukey, $\mathrm{p}<0,05)$.

Tabela 4. Frequências de amostras de leite cru com diferentes níveis de contaminação por microrganismos aeróbios mesófilos (AM) e psicrotróficos (PSI).

\begin{tabular}{ccc}
\hline Níveis de contaminação & AM & PSI \\
\hline (UFC.mL $\left.\mathrm{mL}^{-1}\right)$ & $\mathrm{n}(\%)$ & $\mathrm{n}(\%)$ \\
\hline$<10^{2}$ & $0(0,0)$ & $1(2,4)$ \\
$10^{2}-10^{3}$ & $0(0,0)$ & $6(14,6)$ \\
$10^{3}-10^{4}$ & $1(1,7)$ & $15(36,6)$ \\
$10^{4}-10^{5}$ & $23(38,3)$ & $11(26,8)$ \\
$10^{5}-10^{6}$ & $23(38,3)$ & $3(7,3)$ \\
$10^{6}-10^{7}$ & $7(11,7)$ & $5(12,2)$ \\
$>10^{7}$ & $6(10,0)$ & $0(0,0)$ \\
Total & $60(100,0)$ & $41(100,0)$ \\
\hline
\end{tabular}

grupo na produção leiteira, somada a exigência de refrigeração de toda produção inclusive em temperaturas que podem ser consideradas inadequadas (até $7{ }^{\circ} \mathrm{C}$ em refrigeradores de imersão) (BRASIL, 2002), não existe nenhum parâmetro oficial atualizado para o controle desse grupo em leite cru no Brasil. A refrigeração do leite em tanques de imersão foi a prática relatada pela maioria dos produtores (Tabela 3), com destino da produção para tanques comunitários, procedimento permitido pela IN51 (BRASIL, 2002). Sørhaug, Stepaniak (1997), Pinto et al. (2006) consideram que contagens de PSI a partir de $10^{5}$ a $5 \times 10^{5} \mathrm{UFC}$. $\mathrm{mL}^{-1}$ já são suficientes para promover alterações significativas em derivados. Assim, apenas $8(19,5 \%)$ produtores apresentariam contagens acima de $10^{5}$ UFC.mL ${ }^{-1}$ de PSI (Tabela 4), o que poderia comprometer a qualidade dos derivados produzidos na indústria.

A média de contagem de AM obtidas em propriedades com baixa produção diária $(<50 \mathrm{~L})$ foi menor quando comparada com propriedades de maior produção (> 100 L) (Tabela 3). Em relação à PSI não ocorreram diferenças significativas entre as médias obtidas em propriedades com diferentes volumes de produção diários. Esses resultados sugerem que mesmo com maior produção leiteira, essas propriedades ainda possuem algumas deficiências higiênicas na linha de produção. Entretanto, na comparação das médias obtidas de AM e PSI, considerando diferentes práticas higiênicas adotadas na produção leiteira, observou-se apenas diferença significativa quando a refrigeração é adotada (Figura 1). Apesar de não apresentarem diferenças significativas, a adoção das práticas higiênicas pelos produtores resultou em menores contagens médias de AM e PSI. Os resultados obtidos evidenciaram a importância da refrigeração na produção de leite com qualidade (ARCURI et al., 2006; WALSTRA et al., 1999; GUINOT-THOMAS et al., 1995). Entretanto, apenas a implantação adequada de sistemas de refrigeração, desde que consiga manter o leite em temperaturas não superiores a $4{ }^{\circ} \mathrm{C}$ (CHAMBERS, 2002; WALSTRA et al., 1999), pode manter a qualidade microbiológica da produção, determinada por práticas anteriores a essa etapa.

\section{Conclusões}

Os resultados obtidos indicam que grande parte dos produtores da região estudada adota medidas higiênicas na obtenção e conservação do leite. Os reflexos da adoção desses procedimentos é a alta frequência de produtores de leite com produção dentro dos atuais parâmetros de qualidade estabelecidos pelo MAPA (BRASIL, 2002) e menores contagens médias de AM e PSI. Entretanto, uma prática importante para manter a qualidade e sanidade dos animais, o controle sistemático de mastites pelo $\mathrm{CMT}$, não é realizado pela grande maioria dos produtores. $\mathrm{O}$ procedimento identificado como mais significativo para manter a qualidade do leite foi a refrigeração, que representa uma importante ferramenta desde que aplicada da forma adequada. 


\section{Referências bibliográficas}

ARCURI, E. F. et al. Qualidade microbiológica do leite refrigerado nas fazendas. Arquivo Brasileiro de Medicina Veterinária e Zootecnia, v. 58 , n. 3, p. $440-446,2006$.

BELOTI, V. et al. Avaliação da qualidade do leite cru comercializado em Cornélio Procópio, Paraná. Controle do consumo e da comercialização. Semina: Ciências Agrárias, v. 20, n. 1, p. 12-15, 1999.

BRASIL. Ministério da Agricultura, Pecuária e Abastecimento. Instrução Normativa $\mathrm{n}^{\circ} 51$, de 20 de setembro de 2002. Aprova os Regulamentos Técnicos de produção, identidade e qualidade do leite tipo... Diário Oficial da União, Brasília, 18 de Setembro de 2002. Seção 1.

BRASIL. Ministério da Agricultura, Pecuária e Abastecimento. Instrução Normativa n. 6, de 08 de janeiro de 2004. Aprova regulamento técnico do Programa Nacional de Controle e Erradicação da Brucelose e Tuberculose Animal. Diário Oficial da União, Brasília, 12 de Janeiro de 2004. Seção 1.

BRITO, J. R. F. et al. Adoção de boas práticas agropecuárias em propriedades leiteiras da Região Sudeste do Brasil como um passo para a produção de leite seguro. Acta Scientiae Veterinariae, v. 32, n. 2, p. 125-131, 2004.

CHAMBERS, J. V. The microbiology of raw milk. In: ROBINSON, R. K. (Ed.). Dairy Microbiology Handbook. New York: WileyInterscience, 2002. p. 39-90.

EMBRAPA. GADO DE LEITE. Estatísticas do leite. Juiz de Fora, 2007. Disponível em: <http://www.cnpgl.embrapa.br > Acesso em: 30 de Agosto de 2007.

GRUETZMACHER, T. J.; BRADLEY Jr., R. L. Identification and control of processing variables that affect the quality and safety of fluid milk. Journal of Food Protection, v. 62, n. 6, p. 625-631, 1999.

GUIMARÃES, R. Importância da matéria-prima para a qualidade do leite fluido de consumo. Higiene Alimentar, v. 16, n. 102-103, p. 25-34, 2002.

GUINOT-THOMAS, P.; AMMOURY, M. A.; LAURENT, F. Effects of storage conditions on the composition of raw milk. International Dairy Journal, v. 5, n. 2, p. 211-223, 1995.

KLUNGEL, G. H.; SLAGHUIS, B. A.; HOGEVEEN, H. The effect of the introduction of automatic milking systems on milk quality. Journal of Dairy Science, v. 83, n. 9, p. 1998-2003, 2000.

KOHLMANN, K. L. et al. Production of proteases by psychrotrophic microorganisms. Journal of Dairy Science, v. 74, n. 10, p. 3275-3283, 1991.

LeBLANC, S. J. et al. Major advances in disease prevention in dairy cattle. Journal of Dairy Science, v. 89, n. 4, p. 1267-1279, 2006.

MARTINS, M. L. et al. Genetic diversity of Gram-negative, proteolytic, psychrotrophic bacteria isolated from refrigerated raw milk. International Journal of Food Microbiology, v. 111, n. 2, p. 144-148, 2006.
MUNSCH-ALATOSSAVA, P.; ALATOSSAVA, T. Phenotypic characterization of raw milk-associated psychrotrophic bacteria. Microbiological Research, v. 161, n. 4, p. 334-346, 2006.

NERO, L. A. et al. Leite cru de quatro regiões leiteiras brasileiras: perspectivas de atendimento dos requisitos microbiológicos estabelecidos pela Instrução Normativa 51. Ciência e Tecnologia de Alimentos, v. 25, n. 1, p. 191-195, 2005.

NERO, L. A. et al. Hazards in non-pasteurized milk on retail sale in Brazil: prevalence of Salmonella spp., Listeria monocytogenes and chemical residues. Brazilian Journal of Microbiology, v. 35, n. 3, p. 211-215, 2004.

PINTO, C. L. O.; MARTINS, M. L.; VANETTI, M. C. D. Qualidade microbiológica de leite cru refrigerado e isolamento de bactérias psicrotróficas proteolíticas. Ciência e Tecnologia de Alimentos, v. 26, n. 3, p. 645-651, 2006.

ROCHA, J. S.; BURITI, F. C. A.; SAAD, S. M. I. Condições de processamento e comercialização de queijo-de-minas frescal. Arquivo Brasileiro de Medicina Veterinária e Zootecnia, v. 58, n. 2, p. 263-272, 2006.

RODRIGUES, A. C. O.; RUEGG, P. L. Actions and outcomes of Winscosin dairy farms completing milk quality teams. Journal of Dairy Science, v. 88, n. 7, p. 2672-2680, 2005.

SANTOS, M. V.; FONSECA, L. F. L. Estratégias para controle de mastite e melhoria da qualidade do leite. São Paulo: Manole, 2007. 314 p.

SILVA, Z. N. et al. Isolation and serological identification of enteropathogenic Escherichia coli in pasteurized milk in Brazil. Revista de Saúde Pública, v. 35, n. 4, p. 375-379, 2001.

SILVEIRA, N. V. V. et al. Avaliação das condições físico-químicas e microbiológicas do leite pasteurizado consumido na cidade de São Paulo. Revista do Instituto Adolfo Lutz, v. 49, n. 1, p. 19-25, 1989.

SØRHAUG, T.; STEPANIAK, L. Psychrotrophs and their enzymes in milk and dairy products: quality aspects. Trends in Food Science \& Technology, v. 8, n. 2, p. 35-41, 1997.

VALEEVA, N. I. et al. Improving food safety at the dairy farm level: farmers' and experts' perceptions. Review of Agricultural Economics, v. 27, n. 4, p. 574-592, 2005.

WALSTRA, P. et al. Dairy Technology: principles of milk properties and processes. New York: Marcel Dekker, Inc., 1999. 726 p.

WHER, M. Standard methods for the examination of dairy products. Washington: American Public Health Association, 2004. 570 p. 